\title{
INDICATED MEAN EFFECTIVE PRESSURE OSCILLATIONS IN A NATURAL GAS COMBUSTION ENGINE BY RECURRENCE PLOTS
}

\author{
GRZEGORZ LiTAK \\ Technical University of Lublin, Department of Applied Mechanics, Lublin, Poland; \\ Universita Politecnica delle Marche, Dipartimento di Architettura, Costruzioni e Strutture, Ancona, \\ Italy; e-mail: g.litak@pollub.pl \\ ArkAdIUSZ SyTA \\ Technical University of Lublin, Department of Applied Mathematics, Lublin, Poland \\ BAO-FENG YAO \\ GUO-XIU LI \\ Beijing Jiaotong University, School of Mechanical, Electronic and Control Engineering, Beijing, \\ China
}

We investigate the nonlinear time series of Indicated Mean Effective Pressure (IMEP) of the spark ignition engine cyclic combustion process of a natural gas. By applying the embedding theorem and the recurrence plots technique, we show changes in the engine dynamics for different equivalence ratios. Especially, we provide arguments for intermittency behaviour.

Key words: engine, combustion, recurrence plot, nonlinear oscillations

\section{Introduction}

The problem of harmful cycle-to-cycle fluctuations in combustion was the subject of intensive research in the last few decades (Daily, 1988; Daw et al., 1998; Green et al., 1999; Hu, 1996; Kantor, 1984; Li and Yao, 2008; Litak et al., 2007; Sen et al., 2008; Wagner et al., 2001; Wendeker et al., 2004). Identification of main factors influencing cycle-to-cycle combustion variations by Heywood (1988) shed some more lights on its dynamics. These factors included aerodynamics in the cylinder during combustion, the amount of fuel, air and recycled exhaust gases supplied to the cylinder and the mixture composition near the 
spark plug. It became clear that fluctuations can appear by a non-periodic character of cycle-to-cycle dynamics (Daily, 1988; Green et al., 1999; Kantor, 1984). Basing on the balance of recycled exhaust gases, Daw and collaborators (Daw et al., 1998) derived a simple theoretical model of a lean spark ignition internal combustion process. They supported the hypothesis that the combustion instability develops as a noisy period-doubling bifurcation using the equivalence ratio which as a control parameter by numerical simulations and experiments.

\section{Experimental studies and obtained results}

In this note, we continue experimental investigations in this direction. By decreasing the equivalence ratio from more stoichiometric to very lean conditions in the engine fueled by a natural gas, we observe how combustion fluctuations appear. In spite of the different fuel engine to that examined by Daw et al. (1998), Green et al. (1999), Wagner et al. (2001), the combustion instabilities have the similar nature. These fluctuations seem to depend considerably on the equivalence ratio of the air-fuel mixture. To measure the pressure inside the engine, we used piezoelectric sensors. The schematic picture of our experimental stand is presented in Fig. 1. The engine specifications can be found in Table 1. Further details on our experimental stand can be found in $\mathrm{Li}$ and Yao (2008). After measuring pressure, we have estimated the Indicated Mean Effective Pressure (IMEP) which is defined as the equivalent constant pressure in a given combustion cycle.

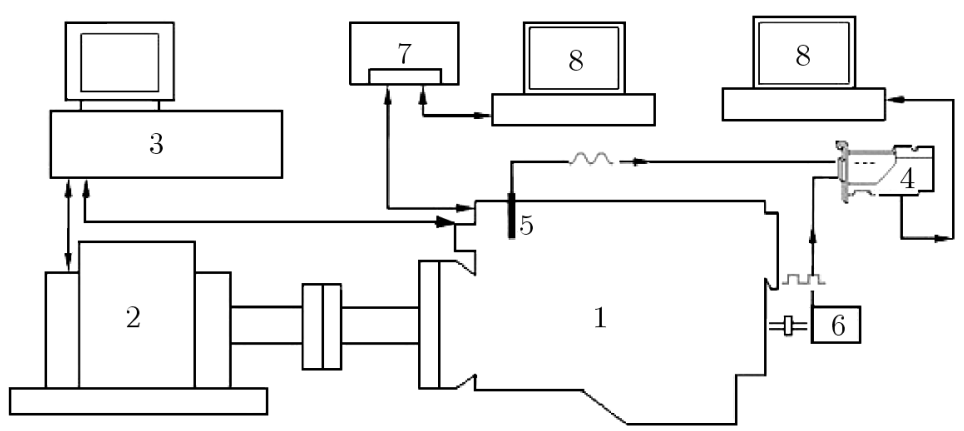

Fig. 1. Scheme of the experimental setup: 1 - engine; 2 - dynamometer;

3 - dynamometer controller; 4 - high-speed data acquisition board; 5 - pressure transducer; 6 - optical encoder; 7 - ECU; 8 - computer 
Table 1. Engine specifications

\begin{tabular}{|l|c|}
\hline Cylinder number & 6 \\
\hline Bore $\times$ store & $126 \mathrm{~mm} \times 130 \mathrm{~mm}$ \\
\hline Displaced volume & $9.726 \mathrm{~L}$ \\
\hline Compression ratio & 10.5 \\
\hline Intake valve opens & $2^{\circ} \mathrm{BTDC}$ \\
\hline Intake valve closes & $208^{\circ} \mathrm{ATDC}$ \\
\hline Exhaust valve opens & $227^{\circ} \mathrm{BTDC}$ \\
\hline Exhaust valve closes & $5^{\circ} \mathrm{ATDC}$ \\
\hline
\end{tabular}

The corresponding plot of IMEP against consecutive cycles $i$ is presented in Fig. 2. Cases 1-4 differ by the decreasing equivalence ratio: $\Phi=0.781,0.677$, 0.595 , and 0.588 .

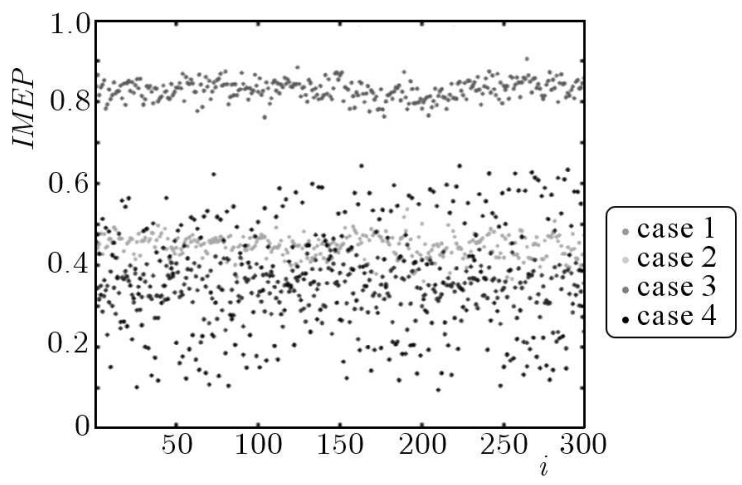

Fig. 2. Cycle-to-cycle changes of $\operatorname{IMEP}(i)[\mathrm{MPa}], i$ enumerates the successive cycle engine. The equivalence ratio was chosen $\Phi=0.781,0.677,0.595$, and 0.588 for cases $1-4$, respectively

Our strategy in analysing these nonlinear time series would be to reconstruct a multidimensional phase space $\boldsymbol{I M E P}$ basing on the scalar $(\operatorname{IMEP}(i))$ time series. Thus for $i>(M-1) \Delta i$

$$
\begin{aligned}
& \boldsymbol{I M E P}= \\
& =\{\operatorname{IMEP}(i-(M-1) \Delta i), \operatorname{IMEP}(i-(M-2) \Delta i), \ldots, \operatorname{IMEP}(i-\Delta i), \operatorname{IMEP}(i)\}
\end{aligned}
$$

where $\Delta i$ and $M$ are the time delay and the characteristic embedding dimension, respectively (Boguś and Merkisz, 2005; Takens, 1981).

These quantities are to be found by a detailed examination of the average mutual information (AMI) (Fraser and Swinney, 1986; Hegger et al., 1999; 
Kantz and Schreiber, 1997) and the false nearest neighbour fraction (FNNF) (Abarbanel, 1996; Hegger et al., 1999; Kennel et al., 1992; Sen et al., 2008). $A M I$ is defined via conditional probabilities of event sequences

$$
A M I(\delta i)=-\sum_{k l} p_{k l}(\delta i) \ln \frac{p_{k l}(\delta i)}{p_{k} p_{l}}
$$

where, for some partition (16 equal parts) of the cyclic effective pressure, $I M E P \in\left[I M E P_{\min }, I M E P_{\max }\right]$. In the above formula $p_{k}$ is the probability to find a time series value in the $k$-th interval, while $p_{k l}$ is the joint probability that an observation falls later into the $l$-th interval. and the observation time is given by $\delta i$.

The optimal time delay $\Delta i=\delta i$ is to be determined by the first $A M I$ minimum for which the examined events are independent enough to define a new coordinate. Note, that $A M I$ is positively defined and its smallest value (theoretically $A M I=0$ ) can be reached when $p_{k l}$ can be factorised to individual probabilities $p_{k}$ and $p_{l}\left(p_{k l} \approx p_{k} p_{l}\right)$ for any $k$ and $l$ far from each other by $\delta i$.

On the other hand, to get a proper $F N N F$, one has to choose the point indicated by $\boldsymbol{I} \boldsymbol{M E} \boldsymbol{P}_{i}$ and calculate the distance to its nearest neighbour point $\boldsymbol{I M E P _ { j }}$ in the $m$-dimensional space. For an Euclidean distance, which is typically used here, it is $\left|\boldsymbol{I} \boldsymbol{M} \boldsymbol{E} \boldsymbol{P}_{i}-\boldsymbol{I} \boldsymbol{M} \boldsymbol{E} \boldsymbol{P}_{j}\right|_{m}$.

By iterating both points along the time series, we compute the control parameter $Q_{i, m}$ defined as

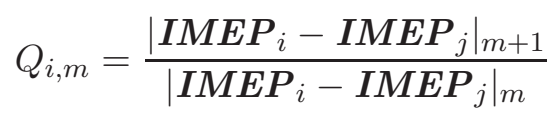

By comparing the above value to a chosen threshold $Q_{c}$, we calculate the fraction of cases for which $Q_{i, m}$ exceeds the threshold value $Q_{c}$. Finally, $F N N F$ can then be estimated from the following expression

$$
F N N F(m)=\frac{1}{N} \sum_{i} \Theta\left(Q_{i, m}-Q_{c}\right)
$$

where $N$ is the number of vector elements in the vector time series, $\Theta(x)$ is the Heaviside step function. This so called fraction analysis is repeated by choosing different values of the dimension $m$. The optimal value $M=m$ is defined when the fraction of false nearest neighbours tends to zero (note, in some cases, depending on the $Q_{c}$ value with respect to the standard square 
deviation of the examined time series $\operatorname{IMEP}(i)$, some points are omitted and $F N N F$ reaches the minimum value for the optimal dimension $m=M$ )

$$
\lim _{m \rightarrow M} F N N F(m) \rightarrow 0
$$

Using the above definitions for $A M I$ (Eq. (2.2)) and FNNF (Eqs. (2.3)(2.5)), we have estimated the embedding for the IMEP time series. Consequently, in Figs. 3a,b, one can easily find that the optimal values are $\Delta i=1$ and $M=5$ for the optimal embedding in all of the considered cases (Fig. 2).

(a)

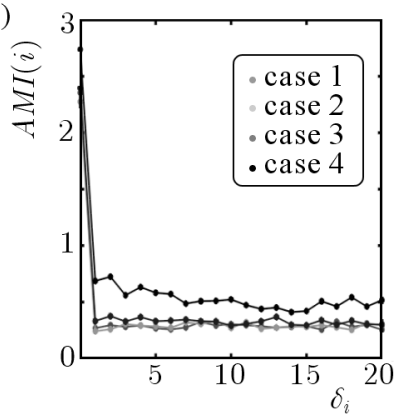

(b)

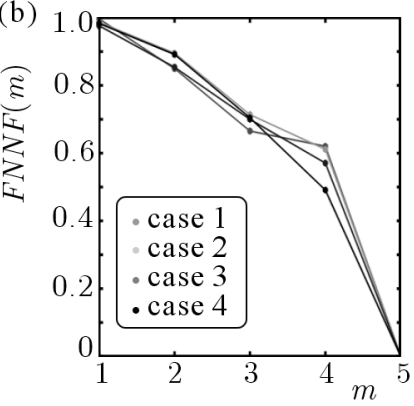

Fig. 3. Average mutual information $(A M I)$ and the false nearest neighbour fraction $(F N N F)$ for all four examined cases 1-4. Basing on Eq. (2.2) and Eqs. (2.3)-(2.5), the embedding parameters $(M, \delta i)=(5,1)$

These initial results on the embedding space presented above would be a natural frame for further recurrence studies: recurrence plots (RP) and recurrence quantification analysis (RQA) techniques. Here, we assumed that these quantities are slowly evaluating during rock cutting.

The recurrence plot is usually defined by the following distance matrix form $\mathbf{R}^{m, \epsilon}$ with the corresponding elements $R_{i j}^{m, \epsilon}$ (Casdagli, 1997; Eckmann et al., 1987; Marwan, 2003, 2006; Marwan et al., 2007; Thiel et al., 2004; Webber and Zbilut, 1994; Wendeker et al., 2004)

$$
R_{i j}^{m, \epsilon}=\Theta\left(\epsilon-\left\|\boldsymbol{I M E} \boldsymbol{P}_{i}-\boldsymbol{I M E P}_{j}\right\|\right)
$$

having 0 and 1 elements to be translated into the recurrence plot as an empty place and a black dot, respectively. In other words, $R_{i j}^{m, \epsilon}=1$ measure the recurrence of the physical state $\boldsymbol{I M E P}$ with the tolerance $\epsilon$. In this method $(\mathrm{RP})$, we examine patterns showing diagonal and vertical or horizontal structures of the lines. After obtaining such a structure, one can easily classify the dynamics of the studied system (Litak et al., 2008a,b; Marwan et al., 2007). 
(a)

(c)
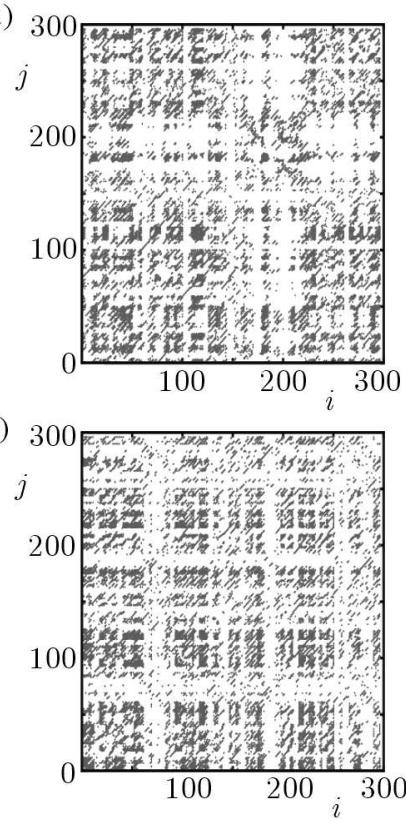

(b)

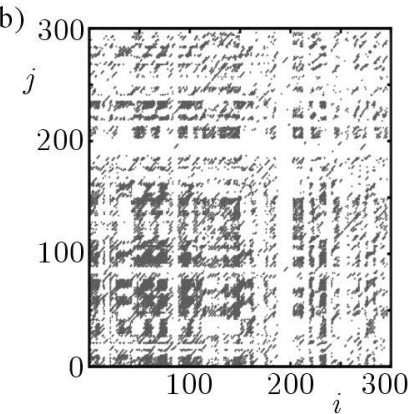

(d)

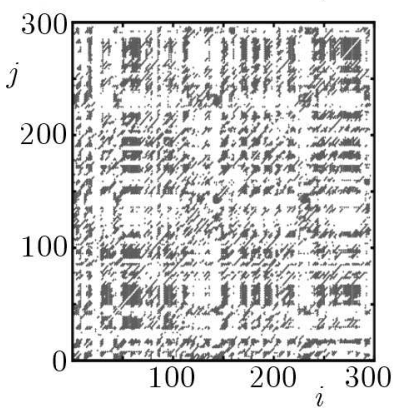

Fig. 4. Recurrence plots of $I M E P$ for four values of the equivalence ratio $\Phi=0.781$,

$0.677,0.595$, and $0.588,(\mathrm{a})-(\mathrm{d})$ respectively. $R R$ was fixed to 0.15 for all cases

In Figs. 4a-d, we mapped the corresponding matrix elements $R_{i j}$ of the investigated cases into recurrence plot graphs.

For quantitative analysis, we define the recurrence rate $R R$

$$
R R=\frac{1}{N^{2}} \sum_{i, j=1}^{N} R_{i j}^{m, \epsilon} \quad \text { for } \quad|i-j| \geqslant w
$$

which determines the black dots fraction in the RP graph. $w$ denotes the Theiler window used to exclude identical and neighbour points of the time series $\boldsymbol{I M E P}$ (see Eq. (2.1) and Fig. 2) from the above summation (Eq. (2.7)). In our case, $w$ was equal 1.

Furthermore, the RQA can be used to identify vertical or diagonal lines through their lengths up to $L_{\max }, V_{\max }$ for diagonal and vertical lines, respectively. In its frame, the RQA enables one to perform probability $p(l)$ or $p(v)$ distribution analysis of the lines according to their length $l$ or $v$ (for diagonal and vertical lines). In practice, they are calculated as

$$
p(y)=\frac{P^{\epsilon}(y)}{\sum_{y=y_{\min }}^{N} P^{\epsilon}(y)}
$$


where $y=l$ or $v$ depending on the diagonal or vertical structures in the specific recurrence plot, $P^{\epsilon}(y)$ is a histogram of the lengths $y$ of the diagonal or vertical lines with the tolerance of recurrence $\epsilon$ (Eq. (2.6)). For various collections of the diagonal and vertical lines with respect to their lengths distributions, Shannon information entropies $\left(L_{E N T R}\right.$ and $\left.V_{E N T R}\right)$ can be defined via (Marwan, 2003)

$$
L_{E N T R}=-\sum_{l=l_{\text {min }}}^{N} p(l) \ln p(l) \quad V_{E N T R}=-\sum_{v=v_{\text {min }}}^{N} p(v) \ln p(v)
$$

Other properties of RP as determinism DET and laminarity $L A M$ as well as the trapping time $T T$ are also based on the probabilities $P^{\epsilon}(x)$

$$
\begin{aligned}
& D E T=\frac{\sum_{l=l_{\text {min }}}^{N} l P^{\epsilon}(l)}{\sum_{i, j=1}^{N} R_{i, j}^{m, \epsilon}} \quad L A M=\frac{\sum_{v=v_{\text {min }}}^{N} v P^{\epsilon}(v)}{\sum_{v=1}^{N} v P^{\epsilon}(v)} \\
& T T=\frac{\sum_{v=v_{\text {min }}}^{N} v P^{\epsilon}(v)}{\sum_{v=v_{\text {min }}}^{N} P^{\epsilon}(v)}
\end{aligned}
$$

In the above equations, $l_{\min }$ and $v_{\min }\left(l_{\min }=v_{\min }=2\right.$ in our case $)$ denote minimal lengths of the diagonal and vertical lines which should be chosen for a specific dynamical system. The determinism quantity $D E T$ is the measure of the predictability of the examined time series and gives the ratio of recurrent points formed in the diagonals to all recurrent points. Note that in a periodic system all points would be included in the lines. On the other hand, the laminarity $L A M$ is a similar measure which corresponds to points formed in the vertical lines. For small point-to-point changes (laminar), the consecutive recurrence points form a vertical line, while turbulent or chaotic changes produce singular points or short lines in the vertical direction. These measures tell about dynamics behind sampling points changes and are strictly connected to the points fraction spanning the diagonal $(D E T)$ and vertical $(L A M)$ patterns, respectively. These diagonal and vertical line patterns form the base of deterministic features, while any singular point corresponds to randomness in the examined system. Note, for random numbers the recurence plot is filled uniformly without any patterns. Finally, the trapping time $T T$ refers to the average length of vertical lines measuring the time scale (in terms of sampling intervals) of these small changes in the examined time history.

We performed calculations (using the numerical code provided in Marwan (2006)) of all the specified quantities for our time series (Fig. 2) and included them into Table 2. For better clarity, we plotted the tendencies of DET 
and $L A M$ in Figs. 5a and 5b, respectively. Interestingly, DET reaches the maximum for the smallest equivalence ratio (case 4). It is associated with the minimum in $L A M$ and a considerable local increase in $T T$ (Table 2).

Table 2. Summary of statistical properties and the recurrence quantification analysis (RQA) of IMEP for different equivalence ratios $\Phi$. The engine speed of $1600 \mathrm{r} / \mathrm{min}$ was fixed for all cases. Note, the embedding parameters $(M, \delta i)=(5,1)$. In all examined cases, $\epsilon$ was appropriately chosen to give the same recurrence rate $R R=0.15$

\begin{tabular}{|c|c|c|c|c|c|c|c|c|c|c|}
\hline $\begin{array}{c}\text { Case } \\
\text { No. }\end{array}$ & $\Phi$ & $\langle$ IMEP $\rangle$ & $\sigma_{I M E P}$ & $D E T$ & $L A M$ & $L_{\max }$ & $V_{\max }$ & $L_{E N T R}$ & $V_{E N T R}$ & $T T$ \\
\hline \hline 1 & 0.781 & 0.829 & 0.0234 & 0.851 & 0.530 & 16 & 21 & 1.831 & 1.246 & 2.853 \\
2 & 0.677 & 0.447 & 0.0276 & 0.864 & 0.564 & 22 & 36 & 1.929 & 1.590 & 3.482 \\
3 & 0.595 & 0.342 & 0.0497 & 0.841 & 0.430 & 17 & 21 & 1.814 & 1.373 & 3.009 \\
4 & 0.588 & 0.376 & 0.1502 & 0.915 & 0.032 & 21 & 10 & 2.136 & 1.545 & 3.344 \\
\hline
\end{tabular}
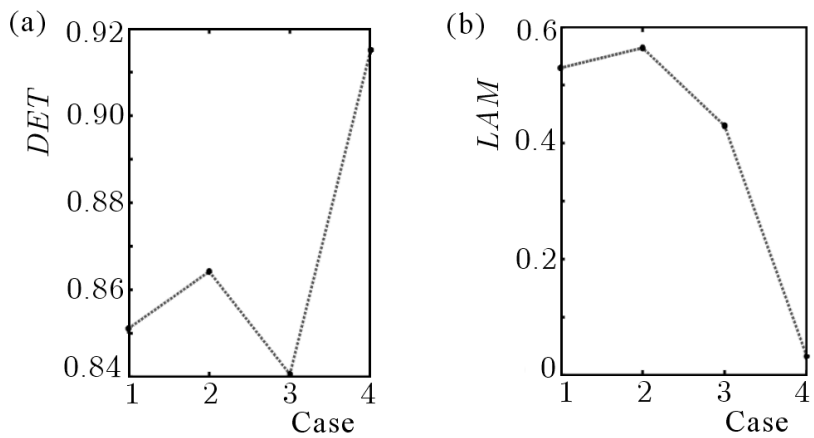

Fig. 5. DET (a) and LAM (b) calculated for measured cases 1-4 (see Fig. 2). In calculations, the $R R$ parameter was fixed to the same value $R R=0.15$

In Figs. 6a and 6b, we plot the corresponding entropies obtained from the diagonal and vertical lines statistics. The considerable increase of $L_{E N T R}$ (case 4) confirms the increasing complexity of the system response for lean combustion. Note that $V_{E N T R}$ also reaches its local maximum for case 4 . On the other hand, basing on the entropy results (Fig. 6), case 3 could be classified as the more periodic as we observe the local minima in $L_{E N T R}$ and $V_{E N T R}$. Surprisingly, $L_{\max }=17$ is relatively short for this case (case 3 ) comparing the neighbour cases (case 2: $L_{\max }=22$, case $4: L_{\max }=21$ ). Finally, the change in $V_{\max }$ is monotonous through cases 2-3-4 with decreasing tendency. Note, the similar tendency was observed for the parameter $L A M$. These symptoms together can be associated with the intermittency bifurcation associated with 
the interrupted system fluctuations of two different types. In the RP diagrams, we should be able to observe characteristic vertical patterns of line collections (Wendeker et al., 2004).
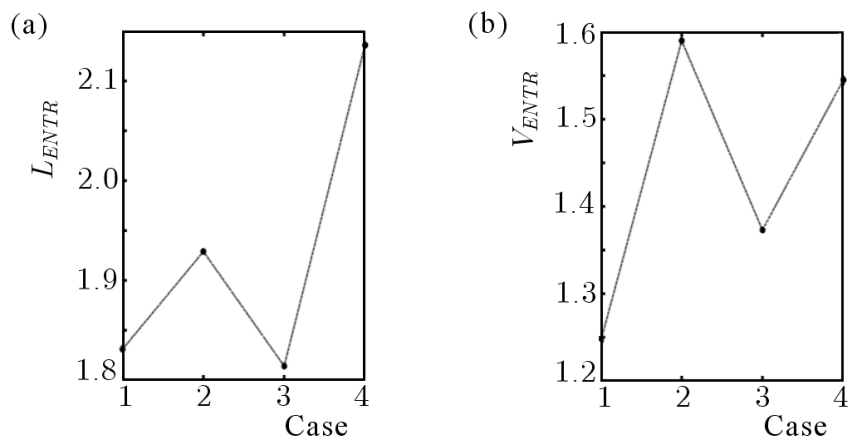

Fig. 6. $L_{E N T R}$ (a) and $V_{E N T R}$ (b) calculated for measured cases 1-4 (see Fig. 2). In calculations, the $R R$ parameter was fixed to the same value $R R=0.15$

In summary, we would like to add that by changing the equivalence ratio $\Phi$ from more stoichiometric to very lean conditions in the engine fueled by a natural gas we observed a dramatic decrease of the laminarity parameter $L A M$ (Fig. 5a) and simultaneous increase of the determinism DET (Fig. 5b). These results could indicate that going to a more lean combustion condition drives the engine to a less stable combustion. Note that this limit was also a subject of investigation by Daw and collaborators (Daw et al., 1998) who discovered chaotic oscillations of heat release in an engine fueled by the petrol fuel. The additional indication supporting this coincidence was a relatively large value of diagonal (Fig. 6a) and vertical (Fig. 6b) lines entropy. Finally, we observe clear features of intermittency. Paying more attention to Figs. 4a-d, one can observe an interesting evolution of the vertical lines. Starting from the most thick, basically square structures in Fig. 4a, we could see a more thin line structure in Fig. 4b and Fig. 4c. The results presented in Fig. 4d look quantitatively different. Here one can distinguish delicate skeletons of the vertical diagonal lines and narrow vertical stripes.

\section{Concluding remarks}

The obtained results from RQA analysis have been related to the traditional statistical measure of square deviation $\sigma_{I M E P}$ (Table 2). One can see that 
$\sigma_{I M E P}$ increases monotonically with decreasing $\Phi$ but the transition from case 3 to 4 is associated with an extremely large increase (about three times) of $\sigma_{I M E P}$. In the same time, the average pressure $\langle I M E P\rangle$ decreases with decreasing $\Phi$ up to case 3 , and then slightly increases in case 4 . This is also a signature of intermittency. Much broader distribution of IMEP in lean combustion conditions must be caused by the effect of alternate less and more efficient combustion cycles. After each relatively bad combustion or misfire in the preceding combustion cycle, the fresh intake charge is mixed with residual gases producing a richer mixture. The richer mixture causes more efficient combustion in the current combustion cycle but their residual gases influence worse the mixture in the next cycle. This effect can be investigated by recurrence plots by considering every second cycle. We have done such an analysis to compare cases 3 and 4 . The relating plots are presented in Fig. 7a and 7b. Comparing these two figures, one can observe the appearance of characteristic 'checkerboard' patterns created by changing $\Phi$ from 0.595 to 0.588 . The clear square-like shape of coloured regions along the diagonal line implies the existence of type I intermittency (Klimaszewska and Żebrowski, 2007; Pomeau and Manneville, 1980).

(a)

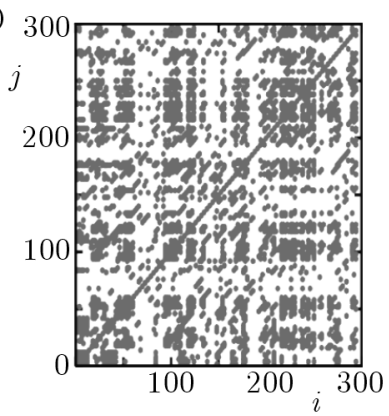

(b)

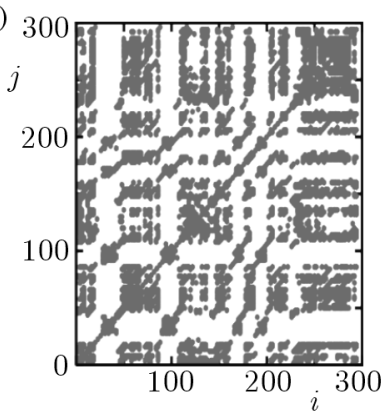

Fig. 7. Recurrence plots IMEP plotted for even (every second) $i$ and $j$ and $\Phi=0.595$ (a), and 0.588 (b). $R R$ was fixed to 0.15 as in Fig. $\dot{4}$, while diagonal points $i=j$ were added here additionally

Note that RP and RQA analyses provide strong arguments that relatively short time series can be investigated by these tools. There are of course a several drawbacks of the method which include the lack of more detailed information about trends and periodics. For instance, larger empty places in RP (Figs. 4a,b) inform about non-stationarities. This effect should be investigated using longer time series or/and using the other measures like the multiscale entropy (Costa et al., 2005). Our results provide important indications to the nature of the combustion process and may be used to the improvement 
of combustion control (Matsumoto et al., 2007). However, to tell more about system efficiency in a particular case one needs to perform more systematic studies including fuel consumption rates.

\section{Acknowledgements}

G.L. has been partially supported by the 6th Framework Programme, Marie Curie Actions, Transfer of Knowledge, Grant No. MTKD-CT-2004-014058 and by the Polish Ministry of Science and Higher Education, Grant No. 9008/B/T02/2007/33.

\section{References}

1. Abarbanel H.D.I., 1996, Analysis of Observed Chaotic Data, Springer, Berlin

2. Boguś P., Merkisz J., 2005, Misfire detection of locomotive diesel engine by non-linear analysis, Mechanical Systems and Signal Processing, 19, 881-899

3. Casdagli M.C., 1997, Recurrence plots revisited, Physica D, 108, 12-44

4. Costa M., Goldberger A.L., Peng C.-K., 2005, Multiscale analysis of biological signals, Phys Rev E, 89, 021906

5. DAily J.W., 1988, Cycle-to-cycle variations: a chaotic process?, Combustion Science and Technology, 57, 149-162

6. Daw C.S., Kennel M.B., Finney C.E.A., Connolly F.T., 1998, Observing and modelling dynamics in an internal combustion engine, Physical Review E, 57, 2811-2819

7. Eckmann J.-P., Kamphorst S.O., Ruelle D., 1987, Recurrence plots of dynamical systems, Europhys. Lett., 5, 973-977

8. Fraser A.M., Swinney H.L., 1986, Independent coordinates for strange attractors from mutual information, Phys. Rev. A, 33, 1134-1140

9. Green J.B. Jr., Daw C.S., Armfield J.S., Finney C.E.A., Wagner R.M., Drallmeier J.A., Kennel M.B., Durbetaki P., 1999, Time irreversibility and comparison of cyclic-variability models, SAE Paper No. 199901-0221

10. Hegger R., Kantz H., Schreiber T., 1999, Practical implementation of nonlinear time series methods: The TISEAN package, Chaos, 9, 413-435

11. Heywood J.B., 1988, Internal Combustion Engine Fundamentals, McGrawHill, New York

12. Hu Z., 1996, Nonlinear instabilities of combustion processes and cycle-to-cycle variations in spark-ignition engines, SAE paper No. 961197 
13. Kantor J.C., 1984, A dynamical instability of spark-ignited engines, Science, 224, 1233-1235

14. Kantz H., Schreiber T., 1997, Non-linear Time Series Analysis, Cambridge University Press, Cambridge

15. Kennel M.B., Brown R., Abarbanel H.D.I., 1992, Determining embedding dimension for phase-space reconstruction using a geometrical construction, Physical Review A, 45, 3403-3411

16. Klimaszewska K., Żebrowski J.J., 2007, Detection of the type of intermittency and the associated bifurcation using characteristic patterns in recurrence plots, preprint

17. Li G.-X., YAo B.-F., 2008, Nonlinear dynamics of cycle-to-cycle combustion variations in a lean-burn natural gas engine, Applied Thermal Engineering, 28, $611-620$

18. Litak G., Gajewski J., Syta A., Jonak J., 2008a, Quantitative estimation of the tools wear effect in a ripping head by recurrence plots, Journal of Theoretical and Applied Mechanics, 46, 521-530

19. Litak G., Kamiński T., Czarnigowski J., Żukowski D., Wendeker M., 2007, Cycle-to-cycle oscillations of heat release in a spark ignition engine, $\mathrm{Mec}$ canica, 42, 423-433

20. Litak G., Sawicki J.T., Kasperek R., 2008b, Cracked rotor detection by recurrence plots, Nondestructive Testing and Evaluation, DOI: $10.1080 / 10589750802570836$, in press

21. Marwan N., 2003, Encounters with Neighbours: Current Development of Concepts Based on Recurrence Plots and their Applications, PhD Thesis, Universität Potsdam, Potsdam

22. Marwan N., 2006, Recurrence Plots Code, http://www.agnld.unipotsdam.de/ marwan/6.download/rp.php

23. Marwan N., Romano M.C., Thiel M., Kurths J., 2007, Recurrence plots for the analysis of complex systems, Physics Reports, 438, 237-329

24. Matsumoto K., Tsuda I., Hosoi Y., 2007, Controlling engine system: a lowdimensional dynamics in a spark ignition engine of a motorcycle, Zeitschrift für Naturforschung, 62A, 587-595

25. Pomeau Y., Manneville P., 1980, Intermittent transition to turbulence in dyssipative dynamical-systems, Communications in Mathematical Physics, 74, 189-197

26. Sen A.K., Longwic R., Litak G., Górski K., 2008, Cycle-to-cycle pressure oscillations in a Diesel engine, Mechanical Systems and Signal Processing, 22, 362-373 
27. TAKens F., 1981, Detecting strange attractors in turbulence, Lecture Notes in Mathematics, 898, Springer, Heidelberg, 366-381

28. Thiel M., Romano M.C., Read P.L., Kurths J., 2004, Estimation of dynamical invariants without embedding by recurrence plots, Chaos, 14, 234-243

29. Wagner R.M., Drallmeier J.A., Daw C.S., 2001, Characterization of lean combustion instability in pre-mixed charge spark ignition engines, International Journal of Engine Research, 1, 301-320

30. WebBer C.L. JR., ZBilut J.P., 1994, Dynamical assessment of physiological systems and states using recurrence plot strategies, J. App. Physiol., 76, 965973

31. Wendeker M., Litak G., Czarnigowski J., Szabelski K., 2004, Nonperiodic oscillations in a spark ignition engine, Int. J. Bifurcation and Chaos, 14, 1801-1806

\section{Analiza wykresów rekurencyjnych dla średniego efektywnego ciśnienia indykowanego $\mathrm{w}$ silniku spalinowym zasilanym gazem naturalnym}

\section{Streszczenie}

Zbadano nieliniowe przebiegi czasowe Średniego Ciśnienia Indykowanego cyklicznego procesu spalania w silniku spalinowym zasilanym gazem naturalnym. Stosujacc twierdzenie o zanurzeniu oraz technikę wykresów rekurencyjnych, pokazano istotne różnice w dynamice silnika przy zmianie składu mieszanki paliwa wyrażonej wartością współczynnika równowagowego. W szczególności podano argumenty przemawiające za występowaniem zjawiska intermitencji.

Manuscript received July 9, 2008; accepted for print October 13, 2008 